\title{
ON THE INFLUENCE EXERTED BY CHLORAL ON THE PAIN OF PARTURITION.
}

\author{
By E. Lambert, Esq., Paris.
}

JUNE $8,1870$.

ThE subject to which I have the honour of drawing the attention of your Society will possess a peculiar interest in your eyes from the fact that it is directly connected with the name of one so justly memorable as Sir James Simpson. It will command this interest at least, that it purports to bring before you and before the profession the facts known to myself in connection with the latter researches of Sir James Simpson in the direction of "obstetric anæsthesia," and I cannot but hope that it may be in the power of others to supplement these by many other observations.

I deeply regret that the few facts here narrated could not be brought collectively under the cognizance of his master-mind, and that I was not permitted to take counsel of his mature experience as thoughts forced themselves upon me during the prosecution of these researches.

When chloral was brought before the profession, Sir James was foremost in prosecuting inquiry into its therapeutic value. I do not know whether he had applied it in private obstetric practice, but his paper on chloral, of 1st January, in the Medical Times, makes reference to the subject. He states that he has seen the parturient womb contract regularly whilst the patient was unconscious. During the last fortnight of the year 1869, he had attended, with my colleague Dr Walker, a case in charge of Dr Somerville, but I have no notes of the results. On the 31st December I requested his attendance; the case is related under No. I.; there was absolute intolerance of the medicine. The next case occurred $2 \mathrm{~d}$ January 1870 , and the important results given in No. II. were observed. 
The last case attended by Sir James Simpson, in connection with the Maternity practice, dates 4th January, No. III. Chloral, it was apparent, could not claim to supplant chloroform, since it abolished consciousness to a less extent, placing the patient as it were midway between conscious and unconsciousness, and rendering her incapable of that control which is essential during the close of the second stage; but this admission only placed in a stronger light the admirable properties of the agent when applied to the relief of pain during the first stage of labour, at a period when it is generally conceded that chloroform is hurtful.

As the hypnotic of this first stage, chloral stands as yet unrivalled; we have only to remember that opium, our only sure refuge, must be administered with the knowledge that we are conspiring, though for a higher end, against the course of labour.

It is with an earnest wish to further the progress of our art that I invite the attention of your Society to the bare statement of the whole facts which have come under my observation. None more than yourselves will feel the interest that attaches to researches in this particular direction-none, I am sure, will be more anxious to employ the keen edge of criticism to the profit of experimental science.

CASE I.-Bridget M'T., aged 25, in her second pregnancy. was admitted to the Maternity Hospital at 8 A.M., 31st December 1869. The os was fully dilated, the membranes entire, the head in first position, resting on the brim of the pelvis. The pains, carefully noted, were recurring about every five minutes from 8.50 A.M. to 10 . Sir James Simpson, accompanied by Dr Jenkins, U.S., and Dr Coghill, attended at 10.15 , and chloral 3 i. was then administered. It was vomited six minutes after; and, at $10.28,3 \mathrm{ij}$. were given in an enema; this was voided five minutes after. At 10.40 the patient had slight rigors, and from 10.45 to 11 there was marked somnolence in the intervals of pain. She then said she felt sleepy, 
but could not sleep, and this sensation passed away shortly. At 11.18 3i. was given and vomited immediately. This was followed by rigors and somnolence, as above, for the space of fifteen minutes. At 11.45 3ij. were administered in an enema, but voided during the next pain. At 12.15 the membranes were ruptured artificially. From 12 to 1 , the bowels were moved twice. The patient had constant eructations, and vomited twice. The labour terminated at 3.45 ; the pains remained throughout efficient.

CASE II.-Agnes P., aged 22. Primipara. Admitted to the Maternity Hospital at 6 P.M., 2d January 1870. At 7.30 the os was the size of a half-crown; the head, first position, was entering the pelvis, the membranes entire. The pains were strong, at very regular intervals of five minutes. In the intervals of pain has constant slight rigors, which become much stronger during the pain. At 9.25 the membranes ruptured spontaneously, and at 9.30 the head was on the perinæum.

- Sir James Simpson attended at 9.50; chloral 3i. was then administered. 9.55.- Says she feels the pains less. At 10,3 i. again given; the rigors ceased, and the patient seemed to sleep in the interval of a pain. At 10.4, she is remarkably calm. At 10.9, there was a slight rigor, then a severe pain, and a sharp cry; and at 10.10 the head was born. Answered questions; said the pains were much less severe since she took the medicine, and that she slept in the intervals. 10.30.-Sleeping very quietly, answered a question, and fell off again immediately. Removed placenta from vagina without any indications of consciousness on the part of the patient. 3.30.-Woke and said, "Where am I?" Hearing her child cry, said, "Whose child is that?" Did not remember birth of child; took food, and slept soundly till morning. Questioned next morning, she affirmed that she only remembered looking up and seeing three doctors; remembered taking the medicine and nothing more; knew nothing of the birth of the child. 
Dr Gordon accompanied Sir James Simpson. She made an excellent recovery. Her child had spina bifida. The case was reported to the Society by Dr C. Bell. Chloral was administered to the infant, whose horrible cries were quieted by it; the spasms were also stopped by its influence.

CASE III.-Margaret O., aged 26. Primipara. Admitted to the Maternity Hospital at 5 P.M., 4th January 1870. Had felt pains since 7 P.M., 3d January. At eight A.M., 4th January, saw a doctor, who told her she was in labour. Took train from Stirling, and was directed to Maternity, Edinburgh.

4th Jan., 5 P.M.-Os size of a shilling, rigid. Membranes entire. Head, first position, entering pelvic cavity. Pains strong.

5th, 12 noon.-No progress. Pains apparently very severe. Patient much excited during their recurrence, and very unruly. Moans constantly during intervals. Has refused food for twenty-four hours. Pains strong, but intermissions irregular, and pain never absent. Sir James Simpson attended at 12.45. Chloral 3i. was given. 1.7.-Marked somnolence during intervals of pain. 1.18-Quiet sleep during intervals. She always gets on her knees during the pains. These appear just as severe, but the intervals are at least two minutes longer, and very regular. She always re-assumes the supine posture before the pain is over, and falls asleep again immediately. 1.48.-Says the pains are very sharp, and complains that medicine is doing no good. Has much difficulty in getting on her knees. Her movements are unsteady. Eyes fixed, haggard; equilibrium uncertain. Ordered not to leave the supine posture. 2.35.-Pains very severe: Still regular. Moans during intervals. 2.48.-Chloral 3i. 3.10.-Perfect repose during intervals of pain. 4.30.-Again becoming agitated and anxious. 5.30.-Os dilated. 7.-Dr Walker ruptured membranes. 7 30.-Chloral 3i. From 7.30 to 10 , when the head was born, this last dose remained efficient. There was always 
quiet sleep during intervals, and the pains were not very sharp. At the exit of the head she showed no sign of greater pain. When all was over she said that the medicine had given her great relief, and pointed especially to the sleep she enjoyed in the intervals. Made same statement next morning.

Observation.-The marked effect in this case was to bring about perfect regularity in the recurrence of pains. These occurred at intervals sensibly longer, and I think it may be fairly stated that the patient was not fully conscious for more than two-thirds of the duration of the pain.

CASE IV.-Mrs C., aged 40; tenth pregnancy; 2 Campbell's Close, Canongate. 8th January 1870.Attended case of Dr Somerville's. Head at brim, first position. Os fully dilated. Pains rare and weak. Dr Somerville reported that she was making no progress for some time back. 1.20 A.M.-Gave Ext. ergot. liq. 3i. 1.32.-Head has entered cavity. 1.35.-Gave chloral 3i. 1.40.-Full, deep respiration, and perfect quietude. 1.45.-Pain apparently less felt. 1.50.-Strong pain. Head on perinæum. 1.55.-Gave chloral 3i. 2.-Sleeping. 2.8.- It is not very evident that she is under the influence of the medicine. Pains follow close upon each other. 2.15.-Head born, much apparent pain.

Observations.-There was a drunken husband, four children, and constant noise and talking. Impossible to obtain quiet, even long after child was born.

8 th Jan., 1 P.M.-Stated that she was conscious throughout. Felt very dizzy after second dose, and wished for sleep. Slept well the remainder of the night, and has done well.

CASE V.-Margaret M`D., aged 18; primipara ; 7 Gullan's Close. In labour since 12 P.M., 12th January 1870. Vomiting a good deal. 4 A.M.-Found os dilated; membranes ruptured; head below brim. Pains regularevery three minutes. Rectum loaded. Enema.-6.30.Pains neither regular nor of any duration. Patient very 
restless; gave chloral 3i. 6.40.-Strong pain after quiet sleep. Complains little during pains, and is very quiet during intervals. 7.5.- Head on perinæum. Gave chloral 3i. 7.10.-Deep sleep. 7.40.-Muttering. Is much agitated. Cannot be kept to any position. Slight delirium. Mother got uneasy; said there was not fair play. Went out, and returned with a midwife. 8 A.M.-By this time the patient was quite quiet. Got rid of the midwife. 8.20.-Child born. Very little exhibition of pain. Cord over shoulder. Child born without much life. Was liberally spanked. Well recovered in three minutes. 8 P.M. - Had slept till a little ago. Remembered nothing, but "skelpin' the backside" (sic). Has done well.

CASE VI.-Mrs F., aged 34; eighth pregnancy; 6 Foulis Close. 13th January 1870.- Sent a nurse to the case, and attended it at 10 P.M. Os size of a shilling. Pains very poor; not regular. 11 P.M.-Hardly any progress. Patient has been living on oat-meal, and drinking a great deal of water. Has constant eructations. Ergot 3i. produced instantly an emetic effect. A quantity of very soursmelling fluid vomited, producing great relief. Pains not improved. 11.25.-Ergot 3i. retained. 11.35.-Vomited a little. 11.50.-Good dilatation. Pushed up anterior lip. 12.15 A.M. - Birth of a female child. Another in utero. Membranes entire. Head presenting. 12.25.-I now gave chloral 3i., trusting to it to get over the second birth unknown to the patient. 12.45.-No progress. Head still at brim. Ruptured membranes, and gave chloral 3 i. 12.52.-Vomited, and continued to vomit frequently. 1.15.-Head at outlet; forehead presenting. The patient was not delivered until 5 A.M. of a female child, dead. I applied forceps in presence of Dr C. Bell, Dr Walker giving chloroform. The patient was quieted for some time by chloral. She was sub-delirious for about half an hour. She slept a good deal.

CASE VII.-Mrs B., aged 19; primipara; 25 College Wynd. Menstruated 5th July 1869. Married 9th July 1869. Fell, going up stairs, 20th January 1870. Woke 
with pains, 22 d January, 8 A.M. At 4 P.M., I found both feet presenting sacro-posterior. 4.30.-Right foot near vulva. 4.40.-Gave conjointly ergot 3 i., chloral 3 i. $\quad 5.10$. -Child born, with exomphalos size of half a large hen's egg; cord $1 \frac{1}{2}$ inches broad. Child $6 \frac{1}{2}$ months. Appeared dead; after twenty minutes of continued efforts it was resuscitated; it lived thirty hours.

CASE VIII.-Anne A., aged 27; second pregnancy; 14 Cowan's Close. At her first labour five years ago, twins, seventh month; had chloroform in the Infirmary, where she was under treatment.

7th February 1870.-Case of Mr M‘Swiney. I attended at 7 P.M. Breech sacro-anterior. She was a terribly unruly patient, and howled at the top of her voice during her pains, although they were not prolonged; she never ceased to ask for chloroform. At 8 P.M., the breech being well in the cavity, I gave conjointly ergot and chloral āa 3i. At 8.4, a prolonged pain, with no exhibition of suffering. At 8.7, making a sort of humming noise. For the next ten minutes, she was in a very excited state, rolling her head from side to side on the pillow, throwing her arms to and fro in cadence, accompanying the motion with an extraordinary gutteral noise; inspiration and expiration both sonorous, the first very short, the second much prolonged; now and again a wild cry at the top of her voice during the pains. Within half an hour from the administration, she was herself, and continued her screams till the birth of the child at 9 P.M. Except whilst she was delirious, she continued to ask for chloroform. The child was at full time; the fotal heart was getting weak when I gave ergot. The labour was not hastened by it, and I could not find any trace of life when the child was born. CASE IX.-Janet B.; primipara; Royal Maternity Hospital. Patient had been suffering for twelve hours, when I was called to see her at 4 A.M., 15th February 1870. Os just admitting extremity of finger ; thin, soft ; membranes entire; pains regular and strong. 9 A.M.Pains are still strong, but recur at rather longer intervals 
( $\frac{1}{4}$ hour). No change in condition of os. 10 A.M.-As above, patient very weary. 11 A.M.-Chloral 3ss., same dose repeated every half hour. 12 noon.-A double dose. 12.30 P.M. - A single dose. 12.45.-A single dose, 3 iii. in all. Up to this time she had been conscious, even during the intervals of pain, getting off her bed during the pains, talking rationally, feeling sleepy, but unable to sleep. The pains recur every seven minutes, are sometimes intercurrent, and of long duration. She was ordered to keep to the bed during the pains; and when examined, the os was found still in the same condition. 12.55.Perfect repose; pulse soft, 88 ; respirations 18 , very easy; pupils normal. She remained for half an hour asleep in a state of the most perfect repose. 1.30.-Believing the anæsthesia to be sufficient, I asked Mr Hinchcliffe, who was present, to examine her; he found the os dilated to size of half-a-crown, and brought away some perfectly fluid blood. Dr Keiller had first arrived, and he examined the patient. Unfortunately the first examination had disturbed the rest, and she was now agitated and complaining, rolling her head on the pillow, and asking for the nurse to support her back. She was, however, but partially conscious. By a singular concurrence of circumstances, a patient in labour with her fourth child was at the same time on the second bed of the Delivery Room, just completing the second stage of a painless labour. This and her former labour ( $3 \mathrm{~d}$ and $4 \mathrm{th}$ ) had been without pain, and the contrast was painfully disadvantageous. 15.5.-Chloral 3ss. 2.10.-Excited, talking much. 2.30. -Quiet and apparently unconscious, notwithstanding the disturbance attending the termination of the other labour and the squalling of the child. 2.40.-Again awake; eyes open naturally for the first time since nearly two hours. Asked her whether that child was hers. Said she thought she could not have got over it so easily. Asked her again whether it was her child. She felt her abdomen and said, No. I was unable to watch the case longer. The labour terminated at 8.30 P.M. Os remained 
as above till 5 P.M., when it began to dilate, and second stage was only one hour.

CASE X.-Jessie R., aged 24; second pregnancy; 19 Vennel. Had her first child at the Edinburgh Maternity, three years ago, under choloroform.

18th February 1870.-On the present occasion was in labour since 12 P.M. 4 P.M.-Head low in cavity ; membranes entire; pains frequent and strong. Ruptured the membranes. Patient very weary, very excitable, crying for choloroform. 4.10.-Gave chloral 3i., and told her it was the new way of giving chloroform. 4.20.-Head was advancing, and anæsthesia not marked; gave chloral 3i. She almost immediately ceased to manifest any excitement; remained quite quiet, and complained no more, not even when the head passed out at 4.40. Twenty-five minutes later, the placenta being still retained in utero, I introduced the hand, and found a portion of it grasped tightly at the left superior angle; withdrawing it, I failed to remove a portion of membranes, and re-introduced the hand, which had to contend with the same cause of retention. Patient perfectly unconscious. About forty minutes after the birth of the child, she began to speak from time to time, and soon opened her eyes. The noise of the child crying prevented her settling down to rest; but she was ignorant of the birth of the infant, and frequently asked "whether she was better-whether she would soon be better." She never inquired whether that child was hers. I had put the binder on over the naked abdomen, and she several times declared that somebody must have carried away her shift. She now began to talk of her mother, who died last August, as if alive, and wondered when she would come. Now and then she slept for a minute or two, and then began again to rave; she talked rapidly, and often changed her subject. She said the doctor had tried to persuade her that was the new way of taking chloroform. "The doctor cheated me-I am sleeping, but I don't know myself-I wish I could sleep; I am very tired" 
(with her eyes shut). "I have tasted that stuff, I wonder what it was-I don't know, but it was not chloroform." Repeated often, “Am I better?" 5.25. -Began to remember that her mother was dead, but on Dr Niven coming in, asked when her mother would be back. Left her at 5.45. 8 P.M.-Found her asleep, and was told she had been talking a great deal of nonsense.

19 th Feb., 10 A.M.-Did not sleep well on account of a cough she had had some time past, otherwise quite well. Remembers the birth of the child-does not remember the removal of the after-birth. Says that the new chloroform is longer putting you over, but that there is not the painful whirring sensation in the head.

CASE XI.-Mrs X., aged 23; primipara; in good health, but much troubled with nervous irritability during her pregnancy. Her dread of pain exceeds any powers of description. Her labour began just after midnight, 9th April. When she could no longer doubt that she was in labour, her excitement and irritability became great. Chloral was administered in 3ss. doses every half-hour from 1.30 to 2.30 A.M. The effect was manifest by the time the second dose was taken, but it seemed desirable to continue the administration, in order to remove some remaining indications of restlessness. From this time, 2.30 to 8 A.M., the pains continued regular and strong; the patient quiet, and perfectly unconscious. An examination made at 6 A.M. showed the os fully dilated, and everything normal. The bladder was emptied with the catheter. At 8, contractions began to flag, and before 10 I wrote to Dr Keiller, advising him of the state of the case. He was in attendance immediately, and examined the patient. Condition of perfect quiet; pupils rather large, but perfectly contractile. No signs of suffering on the part of mother or child. Dr Keiller decided to wait. Labour made no advance. The head remained as above, in good position, but in the middle of the cavity. Towards 2 P.M. the patient became restless, and would not lie long in any position. Rolled the head from side to 
side frequently; no speech. At 3 P.M., Dr Keiller delivered with forceps a male child, which was with difficulty resuscitated, and which remained for twenty-four hours very weakly. Chloroform was administered at the last stage of labour, and its effect was, on the one hand, to quiet the restless agitation, and, on the other, to restore speech, and with this singular result, that the mental preoccupation, which one would have supposed effaced, was revealed as intense as ever; the few words she spoke having reference to her one extravagant preoccupationher labour. The placenta was expelled naturally within ten minutes. She took food that evening, and slept soundly till next morning, feeling perfectly well, but hurt -so that here again her nervousness intervened to retard her recovery; for some slight pain about the parts, when attempting to pass water, alarmed her, and she maintained a voluntary paralysis of the bladder for three weeks, and was only cured of it by the exercise of moral severity. The passage of the catheter left behind much irritation of the bladder. The convalescence was interrupted by an attack of fever - thirty-six hours' duration - on the twelfth day. She gave up nursing five weeks after her confinement; but improper management of the child, from the twelfth to the fifteenth day, must be considered the chief determining cause of this change.

When we are considering the application of chloral to the suppression of pain during labour, the point of primary importance is to determine the influence of the agent on the uterine contractions.

Before proceeding further, I will reserve Cases I., IV., VI., VII., VIII., XI., for future discussion, and confine my remarks for the moment to Cases II., III., V., IX., X., which formed the groundwork of my experimentation.

In Cases II., V., X., the second stage of labour was well advanced, and anæsthesia was as complete as could be desired. Cases III., IX., are severally good types of the two classes of patients we meet with in practice under circumstances of protracted suffering, more especially, as 
in both these instances, there was a tedious first stage. When labour has been protracted until we observe marked distress on the part of the patient, the prominent symptoms are either unnatural excitement or great depression; the pains are irregular, often intercurrent, the intervals not distinctly marked; and who has not heard the patient imploring "a wee sleep?"

In the condition of extreme torture, observed in Case III., the effect of chloral is strikingly exhibited in the case as recorded.

The power of the medicine in diminishing pain was well instanced in this case, when the uterine contractions, tested by the hand on the abdomen, began fifteen or twenty seconds before the patient exhibited any consciousness of pain, which consciousness was again lost before the contraction had expended itself. Intercurrent pains disappeared entirely, and the uterus contracted with a perfectly regular periodicity in periods of longer duration than formerly. Intensity and duration cannot but be a test of efficiency, and my conviction was that the contractions were more efficient. Pain was not superseded, because my experience was not sufficient to allow the exhibition of fuller doses; but in a like case, with much marked reflex excitability, I should like to try conjointly with chloral a very moderate exhibition of chloroform. I should prefer this to increasing the dose of chloral.

The class of patients in whom depression is observed is well exemplified in Case IX. The effect was so marked that the phenomena of labour might have been thought to be suspended. Perfectly painless contractions recurred at very regular intervals, and so effective were they that, in the short space of half-an-hour, the os dilated more than during the preceding wearisome eight hours. Dilatation was so rapid that the structure bled. Acting upon the conclusions drawn from the observations I could command, I secured to a patient, whose nervousness exceeds anything I ever observed, a perfectly painless labour in Case XI. 
I now return to the six Cases I reserved-I., IV., VI., VII., VIII., XI.

CASE I. is an instance of idiosyncrasy-absolute intolerance of the medicine. The results obtained in the four remaining cases are not less interesting that they are negative. In all, ergot was administered conjointly with chloral; and although I confess that the experiments are far too feeble to establish a point of such paramount interest, still I cannot but draw your attention to a subject which observation will readily decide. Is chloral antagonistic to ergot? If so, the therapeutic importance of the fact would hardly outweigh its physiological interest. Dr Liebreich, who introduced chloral to the profession, followed up his researches by the discovery of its antagonism to strychnine; and if my inference is correct, we shall have the two great tetanizing agents, each in its distinct sphere, affecting a like antagonism to chloral.*

I hope I may now be permitted to make a few observations on each case, seriatim, in order to point the interest of each.

CASE I.-Intolerance of medicine.

CASE II.-A very quiet nature of woman, devoid of excitability. Result very favourable. The peculiarity of this case, the first we witnessed, was that the patient several times, during the apparent condition of unconsciousness, answered questions pertinently; in fact, woke out of her sleep to answer them, and fell off at once again. More-she appeared conscious of some pains, and especially of the birth of the head; but the memory of the whole circumstances was effaced when she woke five hours later, and it remained so.

CASE III- A strong, powerful, muscular woman, who came up from the country twelve hours after her labour began, and wandered for a long time in Edinburgh, not knowing where to go. The case has received sufficient comment previously. $\dagger$

* The physiology of this statement is obviously incorrect; the observations are probably defective.-ED. Edin. Medical Journal.

+ See ante, p. 161. 
CASE IV.-Ergot administered before chloral, negative result; other causes tending to negative the hypnotic influence will be referred to further on.

CASE V.-A very remarkable case, quite the parallel of Case II., but complicated with slight cerebral disturbance. Dose too powerful. The girl owed her recollection of the termination of labour to the incident of the commotion produced around her by the resuscitation of the infant.

CASE VI.-Chloral would not have been administered if I could have foreseen the course of labour. This case will be referred to again.

CASE VII.-Ergot administered conjointly with chloral. This case especially suggests antagonism.

CASE VIII.-Marked cerebral disturbance for a short period. This case will also be the subject of critical remarks.

CASE IX.-Perfect anæsthesia for the space of half an hour, interrupted by a vaginal examination.

CASE X.-Very favourable result marred by the occurrence of sub-delirium, more than half an hour after delivery. Hand introduced into uterus, and placenta extracted without any-resistance on the part of the patient.

CASE XI.-Painless labour throughout. Was chloral the cause of the cessation of labour-pains, of uterine contraction? They had continued very efficient for four hours, and the os was fully dilated. They continued two hours more without producing any effect on the head. Is it just to incriminate chloral when we want any correlative proof that it has any tendency to affect injuriously uterine contraction? Before offering any conclusions, I have to add a few remarks on the administration of chloral, presuming that their importance is only secondary in place and not in degree. Sir James Simpson insisted strongly on the influence of external impressions upon the character of the anæsthesia under chloroform, and his rules should be more stringently enforced in the exhibition of an anæsthesia of less potency. What we aim at with any medicine is the attainment of a desired 
end, with the use of the smallest possible quantity. This is especially urgent with a remedy administered by the mouth. Chloral, too, has a very complex action; capable of suppressing reflex action and also consciousness, it seems, when given in excess, occasionally to exercise a stimulant action on the cerebro-spinal system, producing disagreeable effects, not compatible with its introduction to private practice; effects, however, be it said, transient and never dangerous.

On this account it is imperative that the patient be surrounded by conditions tending to perfect repose of mind and body; and when there has been great previous excitement, we must proceed very cautiously. For the attainment of so delicate a result as anæsthesia-"Thus far and no farther"-great care is required, and we must do with chloral as we do with chloroform, administer it tentatively by fractional doses. I have sat for two hours by a pregnant patient brought into the Maternity in the middle of the night, in consequence of severe vomiting; and $I$ have given chloral in successive small doses, watching the case until I knew that perfect rest had been induced; and the next morning, after sound sleep, the cure was perfect. The first successful case I saw treated by Sir James Simpson (Case II.) was a type of good practice, but it was favoured, as no other case has been since, by the general condition under which it occurred"a quiet nature of woman," I have said, "deroid of excitability-a private patient in the hospital, not surrounded by half-a-dozen tattling drones, or curious mutes. Perfect quiet; night time. Case VIII. offers an exact counterpart of this ; the conditions there were most unfavourable for the trial.

It is only when one has observed that one knows the counteracting influence of small things; and though I sincerely believe that the future of painless labour will not rest with chloral, but that science will discover other remedies more applicable still, I am at present only engaged in the chloral experiment, and it is my duty to 
insist upon the conditions of experimentation. Those who, with an honest conviction, say I have never seen such effects, must show henceforth that they have fairly experimented.

In the homes of our Scotch labouring classes, the chamber of a parturient woman is the resort of all the gossips who can gain admittance; whilst the absence of almost every comfort is rarely pushed to the extreme limit of abstinence from stimulants. I made mistakes when I began to experiment, and this warning, if necessary, will prevent their repetition. Cases IV. and VI. were especially refractory, from causes above mentioned. The production of anæsthesia is favoured by all that lulls the senses. I have failed at the Maternity to quiet a wilfully noisy, garrulous patient, even with chloroform, given for nearly an hour to the extent which is permissible in parturition. Chloral given in massive doses to an excited patient, whilst it stupifies consciousness, intensifies reflex irritability-Case VIII.;-Or where it quiets reflex action, may awake unconscious cerebral activity-Case X. Persons present at the administration of anæsthetics in midwifery should therefore be competent to understand suggestions or obey instructions.

Noise must be suppressed; no talking on the part of the patient encouraged; her movements controlled without violence. Examinations and any operative interference should be avoided.

When anæsthesia has been complete and prolonged for some hours, the bladder must be emptied; and it would be advisable, when using the catheter or making a vaginal examination, to avoid the induction of reflex action by giving a few whiffs of chloroform.

In conclusion, I appeal to your indulgence against the possible enthusiasm which has extended this communication beyond reasonable limits.

Conclusions. - 1. Chloral is an agent of great value in the relief of pain during parturition.

2. It may be administered under favourable circum- 
stances during and at the close of the second stage, with the result of producing absolute unconsciousness in the same sense in which we understand unconsciousness under chloroform.

3. When thus given successfully, it has this advantage over chloroform, that it requires no interference with the patient.

4. It is desirable to retain chloroform in the position which it at present occupies in midwifery, and to reserve for the agency of chloral the first stage of labour. If, however, chloral or some agent having analogous properties is found successfully to relieve the pain of uterine contraction, the use of chloroform will be restricted to a lesser period of the duration of labour, or to the facilitation of manual or instrumental interference.

5. It is demonstrated that a labour can be conducted from its commencement to its termination, without any consciousness on the part of the patient, under the sole influence of chloral.

6. The exhibition of chloral in nowise interferes with the exhibition of chloroform.

7. The proper mode of exhibiting chloral is in fractional doses of grs. $x v$. every quarter of an hour until some effect is produced; and according to the nature of that effect the further administration is to be regulated. Some patients will require doses of $3 \mathrm{i}$; ; and it is better to produce an anæsthetic effect by 3 iii. giren in the space of two hours than by 3 i. given singly.

8. The effects of chloral are continued beyond the period of completed parturition, and the repose experienced by the patient after her labour is one of the favourable circumstances to be noted in considering its application to childbirth.

9. Any stimulating effects, in the form of general excitability, occasionally observed during the administration, have passed away very rapidly.

10. Chloral not only does not suspend, but rather promotes uterine contraction by suspending all reflex 
actions which tend to counteract the incitability of the centres of organic motion.

11. Labours under chloral will probably be found to be of shorter duration than when natural, for unconscious contractions appear to have more potent effects than those which are accompanied by sensation of pain.

12. Experiments are required in order to determine whether there exists the same antagonism between ergot and chloral as is known to exist between strychina and chloral.

13. The general conditions under which chloral is to be administered are the same as those which regulate the administration of chloroform, and the rules laid down by Sir James Simpson in connexion with this subject must be rigidly adhered to.

The discussion on Dr Cairn's paper was now proceeded with in connection with the preceding.

Dr Burns said that he had had but little experience of chloral, and that had not proved very satisfactory. In one case of delirium tremens, the second or third dose made the patient sleep for three hours, but the remainder of them did not do him any good. In a second case, a gentleman asked him if he might take it. The first dose rendered him perfectly excited. In two days afterwards, he was called to see the same person. He had taken a dose the night before, and had slept from 10 P.M. to 10 A.M. It was thought he had taken a fit. On my arrival he had much recovered; he had congestion and blueness of the lips and face. He forbade any more chloral being given. In another case in which it was given, it had no effect whatever. His experience, however, was so limited, that he could not give a very definite opinion. In reference to the cases recorded in the paper just read, he considered that they threw very little light on the subject. All the labours mentioned had been very protracted.

Dr Thomson had given it in a case of hysterical neuralgia. In one case he saw, it produced effects so very similar to those of alcoholic intoxication, that it was only from the strong assurance of the medical man in attendance that she had got nothing but chloral, that he was enabled 
to form the idea that they did not arise from stimulants. In another case, no rest could be got at night without the chloral. In the case of this patient, he recommended her removal from her family. In another case of neuralgia of the left breast, many things were tried; she had large doses of opiates and bromide of potassium without avail; 20 grains of chloral, or 6 grains at bed-time, had given her a most excellent sleep. Afterwards, when the pain again resumed its former severe character, he thought that some internal organic disease might be present; and accordingly, after death, he found a tumour in the thorax and observed caries of the ribs posteriorly, about the centre of the back. The neuralgia was caused by the disease of the bone. There was also inability to pass urine; very much to his annoyance, as it had to be removed. He felt disinclined to use it in ordinary cases of parturition-he preferred chloroform ; besides, it was a depressing agent, from which the patient did not readily recover.

Dr James Young said that he had used chloral largely, and found it most serviceable as a hypnotic, inducing sleep and relieving pain, in doses of half a drachm. In delirium tremens it was especially beneficial. In the case of a gentleman in Princes Street, whom he had seen lately, it was of the greatest use. The patient was violent and unreasonable, and had slept none for several nights. He was induced to go to bed, and had one drachm of the hydrate of chloral administered. He slept several hours, and awoke comparatively well. Next night he had another drachm, and on the following day went to his business. In cases of severe nervous headache, he had seen quiet sleep, with relief, produced by drachm doses. He had a lady patient residing in France, who wrote him that she could get no sleep in consequence of intense headache. He sent her a prescription for chloral, and by a letter he had received, she stated that the relief derived was inconceivable. Dr Young said he had used chloral in cases of infantile convulsions in doses of one and two grains, with marked benefit in checking the convulsions and inducing sleep. In cancer, he had used it frequently with good results.

Dr Cairns made some remarks in reply to observations on his paper. 